\title{
Synthesis of ZnO Nanoparticles by Using an Atmospheric-Pressure Plasma Jet
}

\author{
Eidan Asi Abdullah, Ahmed Abed Anber, Farqad Fisal Edan, Ali Jabbar Fraih \\ Department of Physics, College of Science, University of Wasit, Al Kut, Iraq \\ Email: eidan@uowasit.edu.iq, Ahmedkrm88@gmail.com
}

How to cite this paper: Abdullah, E.A., Anber, A.A., Edan, F.F. and Fraih, A.J. (2018) Synthesis of ZnO Nanoparticles by Using an Atmospheric-Pressure Plasma Jet. Open Access Library Journal, 5: e4755. https://doi.org/10.4236/oalib.1104755

Received: July 5, 2018

Accepted: July 21, 2018

Published: July 24, 2018

Copyright $\odot 2018$ by authors and Open Access Library Inc.

This work is licensed under the Creative Commons Attribution International License (CC BY 4.0).

http://creativecommons.org/licenses/by/4.0/ (c) (i) Open Access

\begin{abstract}
In this study, zinc oxide nanoparticles were synthesized by using an atmospheric-pressure plasma jet in $\mathrm{NaOH}-\mathrm{HNO}_{3}$ electrolytic system. Atmospheric-Pressure Plasma Jet was successfully used as the cathode and Znsheet was used as the anode. The characterization of zinc oxide was obtained by X-ray powder diffraction (XRD), Fourier transformation infra-red (FTIR) and transmission electron microscope (TEM). The results show that the morphology of zincoxide nanocrystals obtained by this technology is mainly dependent on the electrolytic media, current density and reaction temperature. The average grain size of $\mathrm{ZnO}$ nanoparticles is around $50.4 \mathrm{~nm}$. These results encourage preparing these nanostructures for using in a great interest applications in solar cells, UV light emitting diodes, gassensors, etc. This technique is low cost, scalable and general and should allow a wide range of nanoparticle materials to be synthesized in the gas or liquid phase.
\end{abstract}

\section{Subject Areas}

Plasma

\section{Keywords}

Zinc Oxide, Atmospheric Pressure Plasma Jet, Electrolytic System,

Nanostructures

\section{Introduction}

In this study, a simple atmospheric plasma jet electrochemical technique is reported, where the plasma takes place at the gas-solution interface as the cathode for the synthesis of zinc oxide nanoparticles. Much interest was focused on exploring the effects of various process parameters such as the type of electrolyte, stirring, current density and temperature on the growth of zinc oxide nano- 
structures. Moreover, the possible formation mechanism for the zinc oxide nanoparticles synthesized by the newest plasma-liquid electrochemical technology is discussed. Zinc oxide nanostructures have received a great interest due to potential applications in transparent electrodes, solar cells, blue/UV light emitting diodes, and sensors. [1] [2]. Stimulated by these applications significant attempts have been made in recent years to design $\mathrm{ZnO}$-based composite nanostructures, such as doped and heterostructure nanocrystals. The composite nanostructures exhibit new optical and electronic properties due to the different functionality of their components. For example, the metal/semiconductor nanojunctions are being extensively studied for these purposes.

Up to now, $\mathrm{ZnO}$ nanostructures with various shapes have been synthesized by different methods including hydrothermal method, electrochemical rout [3] [4] [5] [6] [7], chemical vapor deposition of precursors [8], solution synthesis method [9] and chemical method [10]. However, so far, no report has been researched on the synthesis of zinc oxide by atmospheric plasma-liquid electrochemistry technology. The atmospheric-pressure plasma jets have enormous interest from the plasma organization due to their characteristics of small physical size, excimer generation [11] [12] [13], atmospheric pressure stability [14] and non-equilibrium thermodynamics [15] [16]. These properties make atmospheric plasmas suitable for a wide range of applications, including medicine, gas treatment, textiles, surface modification and nanofabrication [17].

\section{Experiment}

Zinc oxide nanoparticles were synthesized by atmospheric plasma jet. A schematic diagram of the experimental set-up and a photograph of the discharge are shown in Figure 1. The system consist of a tube acted as the cathode made of stainless steel with $0.6 \mathrm{~mm}$ inner diameter and length is $7 \mathrm{~cm}$, it was located $3 \mathrm{~cm}$ away from the zinc electrode. The zinc sheet acted as the anode $(5 \mathrm{~cm}$ width, 10 $\mathrm{cm}$ length, immersion area is $2 \mathrm{~cm}^{2}$ ) with a gap of $3 \mathrm{~mm}$ between the tube end and the liquid surface. Argon gas flow was coupled to the tube and controlled by a glass flow meter at $60 \mathrm{ml} / \mathrm{min}$. There action was occurred in glass basin, with width of $5.5 \mathrm{~cm}$ and length of $8.5 \mathrm{~cm}$. The zinc anode was polished and washed with distilled water, and then immerged into electrolyte containing $1 \mathrm{~g} / \mathrm{LNaOH}$ and $1.3 \mathrm{~g} / \mathrm{L} \mathrm{HNO}_{3}$ and $1 \mathrm{~g} / \mathrm{L}$ glucose (fructose) as stabilizers to prevent uncontrolled particle growth and agglomeration with the distilled water. The discharge was ignited by applying of a high voltage of $3 \mathrm{kV}$ with $40 \mathrm{KHz}$ using AC power supply. The discharge current was kept constant in the range of $5-10 \mathrm{~mA}$. The electrolyte was exposure at different time, $(15,30$ and $45 \mathrm{~min})$ and it can be observed the electrolyte systems shown in Figure 2. At the end of the synthesis, the sediments were centrifuged and washed with deionized water and ethanol for several times. Subsequently, the obtained products were dried at $60^{\circ} \mathrm{C}$ for $2 \mathrm{~h}$.

\section{Results and Discussion}

Figure 3 shows the XRD patterns of the zinc oxide nanoparticles. It is no peak at 


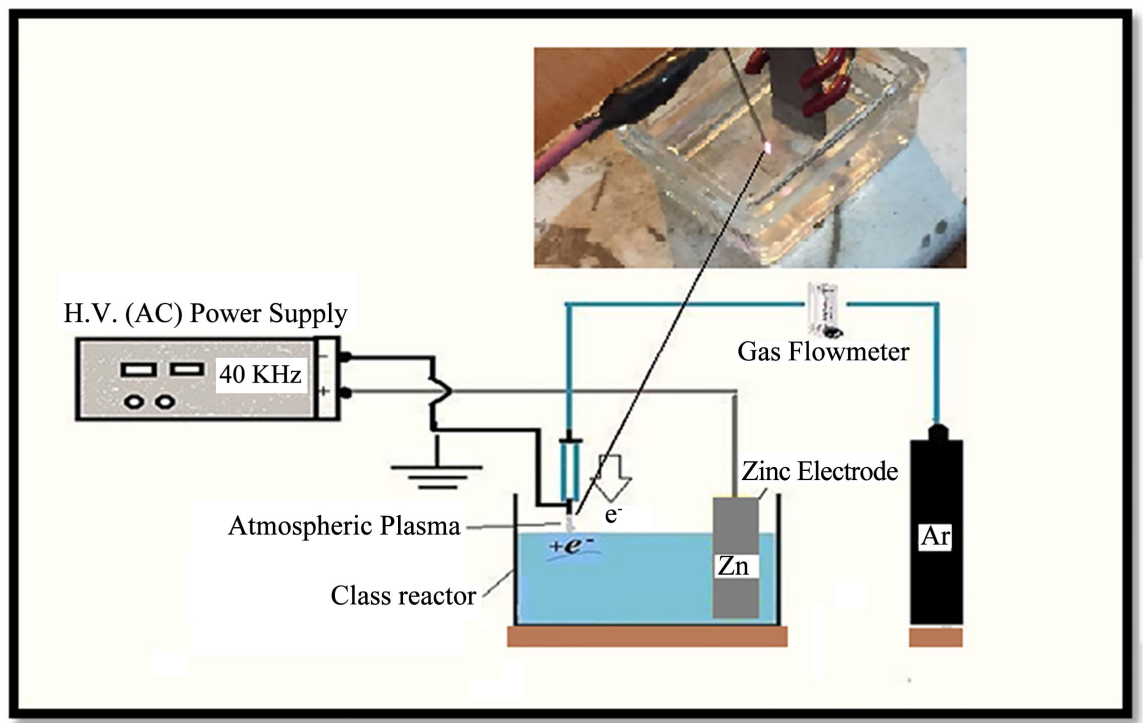

Figure 1. The schematic diagram of atmospheric plasma jet electrochemical synthesis of zinc oxide nanoparticles.

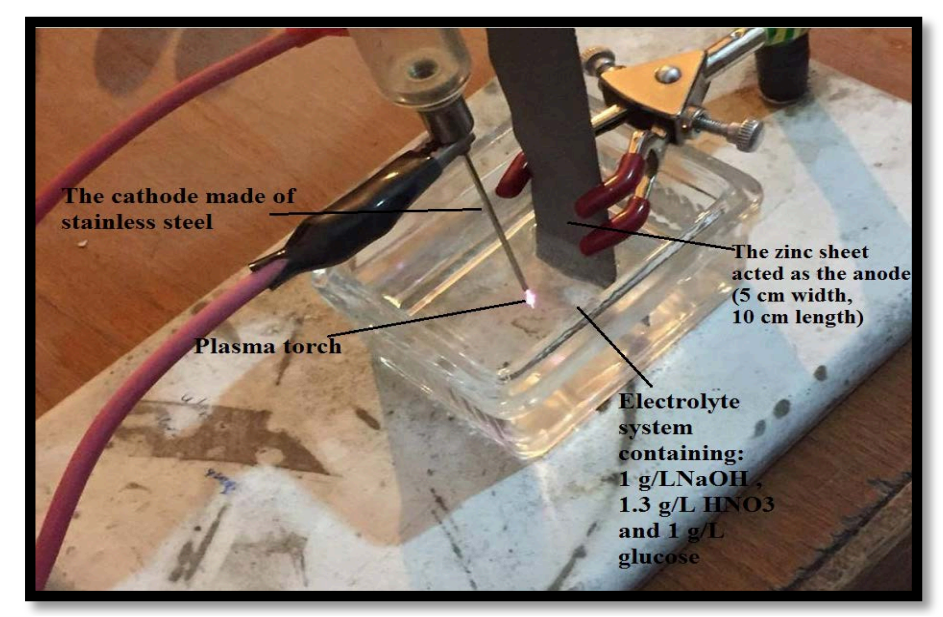

Figure 2. (Color online) at different discharge duration. The discharge current is $5 \mathrm{~mA}$. The gap length is $3 \mathrm{~mm}$.

preparation time $15 \mathrm{~min}$ as shown in Figure 3(a), while when increasing preparation time $45 \mathrm{~min}$ it can be observe two peaks $34.45^{\circ}$ and $38.1^{\circ}$, that are in well agreement with those for zinc oxide nanocrystals obtained from the International Center for Diffraction Data, USA (1979) JCPDS 1979, C 29-1133, (Joint Committee on Powder Standards) as shown in Figure 3(b). This color of products could visually be seen from Figure 4 . FTIR was used to estimate the chemical bonding configurations in the sediments zinc oxide nanoparticles. The recorded transmission spectra were in the range of $400-4000 \mathrm{~cm}^{-1}$. Figures 5 , shows that the peak observed at 3452.30 and $1119.15 \mathrm{~cm}^{-1}$ are may be due to $\mathrm{O}-\mathrm{H}$ stretching and deformation, respectively assigned to the water adsorption on the metal surface. The peaks at $1634.00,620.93 \mathrm{~cm}^{-1}$ are belonging to $\mathrm{Zn}-\mathrm{O}$ stretching and deformation vibration, respectively. Themetal-oxygen frequencies 
observed for the respective metal oxides are in accordance with literature values [18] [19]. V. Parthasarathi and G. Thilagavathi [20] reported similar FTIR spectra observed of zinc oxide nanoparticles in their investigation.

Transmission electron microscope for the prepared zinc oxide nanoparticles are shown in Figure 6. Dot shape $\mathrm{ZnO}$ nanoparticles were observed in TEM images of average size in the around $10-15 \mathrm{~nm}$ as shown in Figure 6(b) when the preparation time was increased and indicates that the particles are well crystallized.

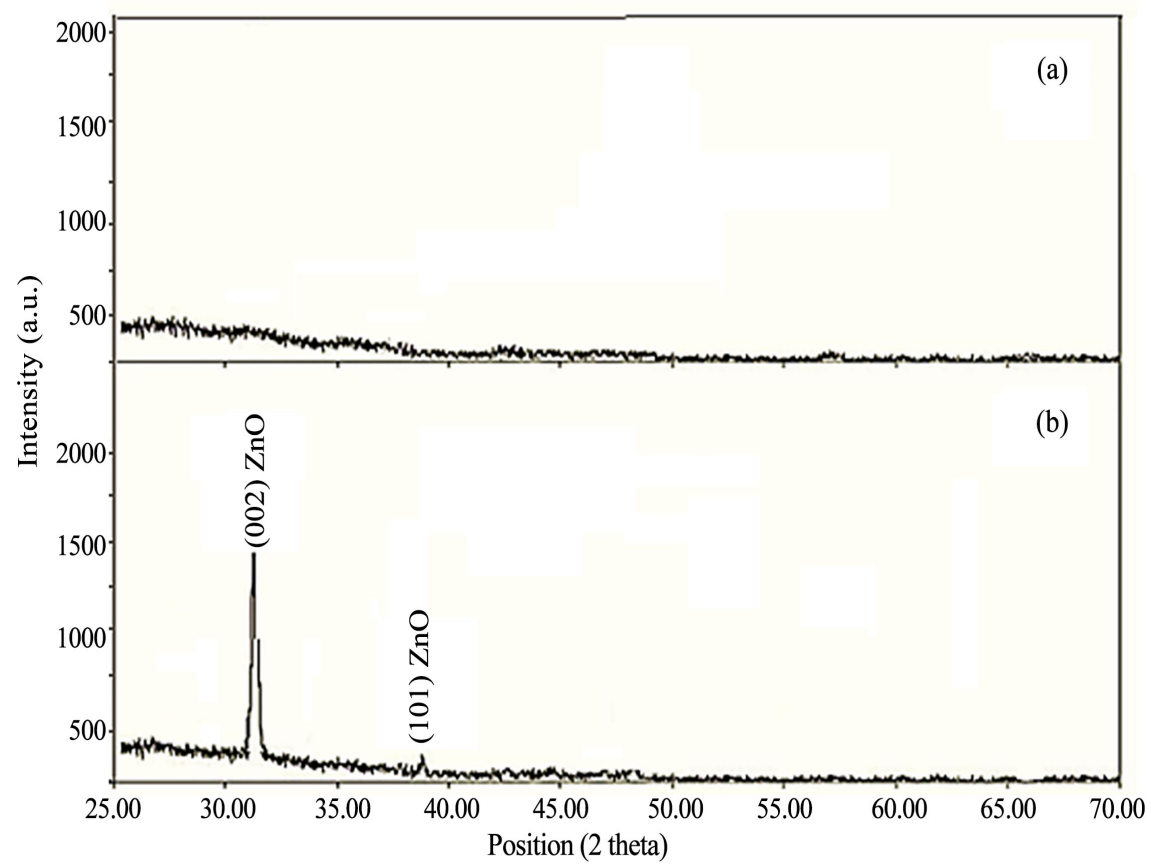

Figure 3. The XRD patterns of $\mathrm{ZnO}$ powder prepared by atmospheric pressure plasma jet electrochemical method in different compositions. (a) $15 \mathrm{~min}$; (b) $45 \mathrm{~min}$.

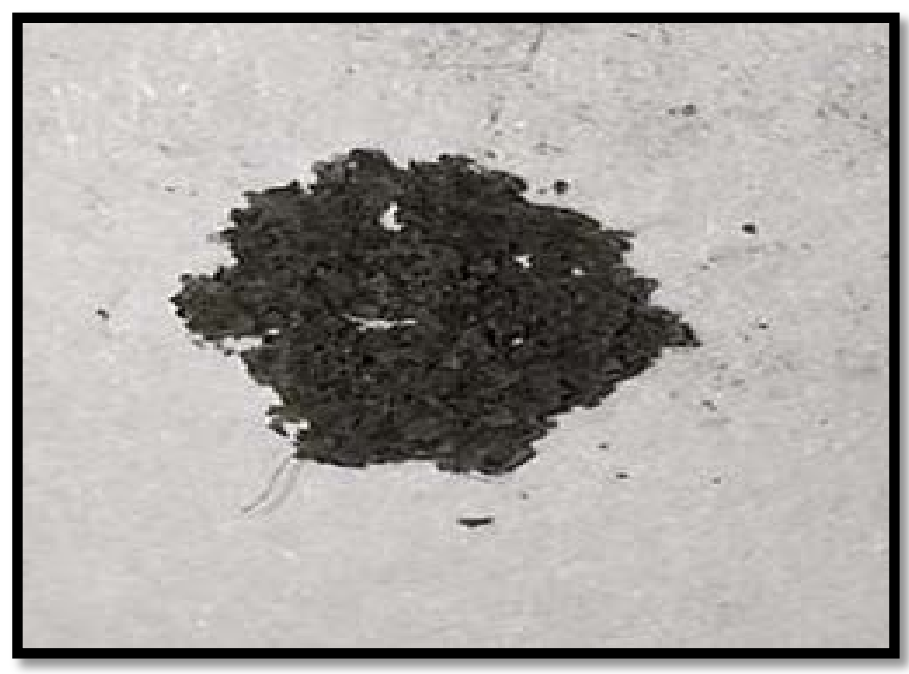

Figure 4. The pictures of $\mathrm{ZnO}$ powder (The sediment was centrifuged to investigate by XRD). 


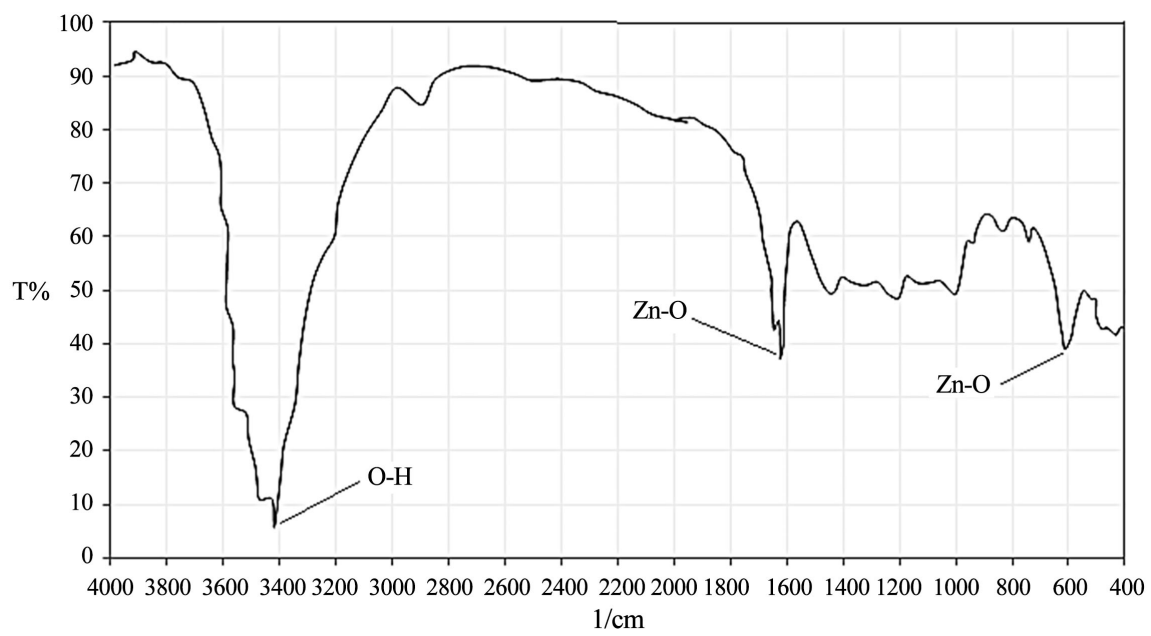

Figure 5. FTIR spectra of the zinc oxide nanostructures prepared in this work at $45 \mathrm{~min}$ preparation time.

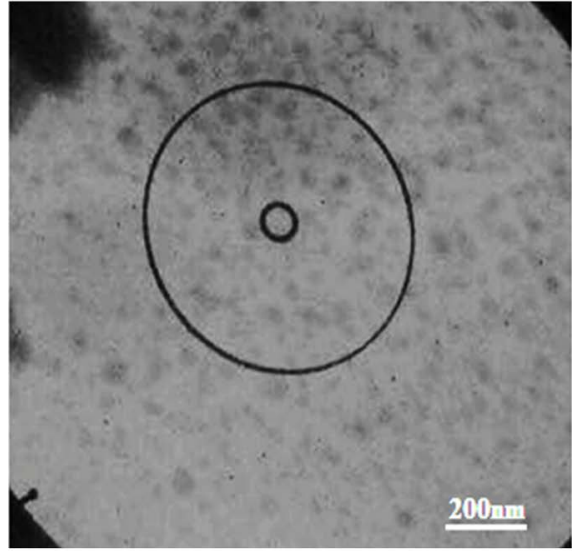

(a)

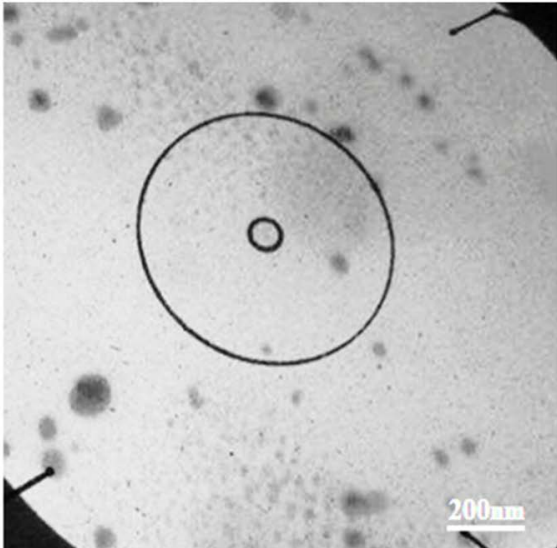

(b)

Figure 6. TEM images of $\mathrm{ZnO}$ nanoparticles prepared at preparation time (a) $15 \mathrm{~min}$; (b) $45 \mathrm{~min}$

\section{Conclusion}

In this work, it was observed the capabilities atmospheric-pressure plasma jet to prepare zinc oxidenanometer-sized, uniform, high-purityin the gas or liquid phase. However, the theoretical fundamental of this method is new. Therefore, more efforts should be undertaken to demonstrate the present results to exploit this atmospheric-pressure plasma jet technology. The prepared zinc oxide nanoparticles have a widely application prospects in environmental governance. This result can be considered high and the work can be good attempt to prepare zinc oxide via atmospheric-pressure plasma jet as a new method and employ nanostructures in such important application.

\section{Acknowledgements}

Authors would like to thank ministry of Science and Technology, Renewable Energy Directorate, Solar Energy Research Center for their assistance to perform 
the machining work of the measurements.

\section{Conflicts of Interest}

The authors declare no conflicts of interest regarding the publication of this paper.

\section{References}

[1] Kolodziejczak-Radzimska, A. and Jesionowski, T. (2014) Zinc Oxide-From Synthesis to Application: A Review. Materials, 7, 2833-2881.

https://doi.org/10.3390/ma7042833

[2] Klingshirn, C.F., Meyer, B.K., Waag, A., Hoffmann, A. and Geurts, J. (2010) Zinc Oxide: From Fundamental Properties towards Novel Applications. Springer, New York. https://doi.org/10.1007/978-3-642-10577-7

[3] Lu, Y., Xu, S.F., Zhong, X.X., Ostrikov, K., Cvelbar, U. and Mariotti, D. (2013) Characterization of a DC-Driven Microplasma between a Capillary Tube and Water Surface. Europhysics Letters, 102, 15002. https://doi.org/10.1209/0295-5075/102/15002

[4] Zeng, H.B., Cai, W.P., Li, Y., Hu, J.L. and Liu, P.S. (2005) Composition/Structural Evolution and Optical Properties of $\mathrm{ZnO} / \mathrm{Zn}$ Nanoparticles by Laser Ablation in Liquid Media. The Journal of Physical Chemistry B, 109, 18260-18266. https://doi.org/10.1021/jp052258n

[5] Richmonds, C. and Sankaran, R.M. (2008) Plasma-Liquid Electrochemistry: Rapid Synthesis of Colloidal Metal Nanoparticles by Microplasma Reduction of Aqueous Cations. Applied Physics Letters, 93, Article ID: 131501. https://doi.org/10.1063/1.2988283

[6] Jana, S., Vuk, A.S., Mallick, A., Orel, B. and Biswas, P.K. (2011) Effect of Boron Doping on optical Properties of Sol-Gel Based Nanostructured Zinc Oxide Films on Glass. Materials Research Bulletin, 46, 2392-2397. https://doi.org/10.1016/j.materresbull.2011.08.038

[7] Dutta, S., Chattopadhyay, S., Sarkar, A., Chakrabarti, M., Sanyal, D. and Jana, D. (2009) Role of Defects in Tailoring Structural, Electrical and Optical Properties of ZnO. Progress in Materials Science, 54, 89-136. https://doi.org/10.1016/j.pmatsci.2008.07.002

[8] Shan, G., Xu, L., Wang, G. and Liu, Y. (2007) Enhanced Raman Scattering of ZnO Quantum Dots on Silver Colloids. The Journal of Chemical Physics, 111, 3290.

[9] Hasuike, N., Deguchi, R., Katoh, H., Kisoda, K., Nishio, K., Isshiki, T. and Harima, H. (2007) Structural Properties of Nanometre-Sized ZnO Crystals Doped with Co. Journal of Physics. Condensed Matter, 19, Article ID: 365223. https://doi.org/10.1088/0953-8984/19/36/365223

[10] Jusserand, B. and Cardona, M. (1989) Phonon Dispersion in GaAs Journal of Applied Physics, 66, 48.

[11] El-Habachi, A. and Schoenbach, K.H. (1998) Generation of Intense Excimer Radiation from High-Pressure Hollow Cathode Discharges. Applied Physics Letters, 73, 885. https://doi.org/10.1063/1.122027

[12] Sankaran, R.M., Giapis, K.P., Moselhy, M. and Schoenbach, K.H. (2003) Argon Excimeremission from High-Pressure Microdischarges in Metal Capillaries. Applied 
Physics Letters, 83, 4728.

[13] Park, S.J., Eden, J.G., Chen, J. and Liu, C. (2004) Microdischarge Devices with 10 or $30 \mu \mathrm{m}$ Square Silicon Cathode Cavities: Pd Scaling and Production of the $\mathrm{XeO} \mathrm{Ex}-$ cimer. Applied Physics Letters, 85, 4869. https://doi.org/10.1063/1.1825061

[14] Park, S.J. and Eden, J.G. (2002) 13-30 Micron Diameter Microdischarge Devices: Atomicion and Molecular Emission at above Atmospheric Pressures. Applied Physics Letters, 81, 4127. https://doi.org/10.1063/1.1520707

[15] Kurunczia, P., Abramzona, N., Figusb, M. and Becker, K. (2004) Measurement of Rotational Temperatures in High-Pressure Microhollow Cathode (MHC) and Capillary Plasma Electrode (CPE) Discharges. Acta Physica Slovaca, 54, 115-124.

[16] Penache, C., et al. (2002) Characterization of a High-Pressure Microdischarge Using Diode Laser Atomic Absorption Spectroscopy. Plasma Sources Science and Technology, 11, 476-483. https://doi.org/10.1088/0963-0252/11/4/314

[17] Mariotti, D. and Sankaran, R.M. (2011) Perspectives on Atmospheric-Pressure Plasmas for Nanofabrication. Journal of Physics D: Applied Physics, 44, Article ID: 174023. https://doi.org/10.1088/0022-3727/44/17/174023

[18] Rao, C.N.R. (1963) Chemical Applications of Infrared Spectroscopy. Academic Press, New York and London.

[19] Markova-Deneva, I. (2010) Infrared Spectroscopy Investigation of Metallic Nanoparticles Based on Copper, Cobalt, and Nickel Synthesized through Borohydride Reduction Method. Journal of the University of Chemical Technology and Metallurgy, 45, 351-378.

[20] Parthasarathi, V. and Thilagavathi, G. (2012) Synthesis and Characterization of Zinc Oxide Nanopartilce and Its Application on Fabrics for Microbe Resistant Defence Clothing. International Journal of Pharmaceutical Science, 3, 1-7. 